\title{
Dynamic aspects of guinea pig inner hair cell receptor potentials with transient asphyxia
}

\author{
Alfred L. Nuttall \\ Kresge Hearing Research Insime, University of Michigan, Ann Arbor, MI 48109, U.S.A.
}

(Received 26 March 1984; accepted 11 July 1984)

\begin{abstract}
$D C$ and $A C$ receptor potentials of cochlear inner hair cells in response to tone bursts of various frequencies and intensilies were continuously measured during and following periods of transient asphyxia. The effects of asphyxia were most pronounced for low sound pressure level (SPL) acoustic stimuli near the characteristic frequency (CF) of the inner hair cell, leading to vulnerability of the 'tip' of the cell's frequency tuning curve (FTC). The resulting changes in the shape of the FTC are, first, a reduction in tip criterion sensitivity of 10-20 dB without significant loss in sharpness of tuning. Later, when the full effect of $30-45 \mathrm{~s}$ asphyxia occurs, tip sensitivity loss between 30 and $65 \mathrm{~dB}$ is accompanied by greatly broadened tuning and a shift downward in frequency of the CF by greater than $1 / 4$ octave. The CF shift is due to a progressive loss of high frequency sensitivity. The linear segment of the input-output (intensity) function, plotted as $\log$ DC receptor potential versus SPL (at the original CF), becomes longer during the early phase asphyxia, and the slope of the segment declines by $50 \%$. At high SPLs, for all frequencies, the time course of the receptor potential change was similar in shape to that exhibited by the endocochlear potential (EP). In particular, for high sound levels, the recovery of response matches the EP while for low level tip frequency sounds recovery is protracted. No difference between the decline of the $A C$ and DC receptor potentials at CF was observed. Inner hair cell resting mernbrane potential ( $E_{\mathrm{m}}$ ) hyperpolarized during asphyxia by 2-6 $\mathrm{mV}$, correlating with the change in EP according to a ratio of $1 / 10\left(E_{\mathrm{m}} / \mathrm{EP}\right)$.
\end{abstract}

cochlear hair cell, receptor potential, asphyxia, endocochlear potential

\section{Introduction}

The sound-evoked responses of cochlear inner hair cells (IHCs) have been shown to be highly vulnerable to transient asphyxia [5,36]. Given that the majority of auditory afferent neurons innervate the inner hair cells [46], one significance of this finding is that the well known sensitivity of the auditory nerve potentials under hypoxia $[2,10,15,25]$ is largely accounted for by inner hair cell response changes. The general character of tuning changes seen for hypoxic neurons [12] is equivalent to that observed for inner hair cells and no further physiological degradation due to hypoxic effects on the neuron need be invoked. The most prominently vulnerable feature of both the IHC and the auditory nerve fiber is the sharply tuned 'tip' portion of the frequency tuning curve (FTC). During a short period of transient asphyxia when the low frequency 'tail' portion of the FTC may be only slightly shifted toward reduced sensitivity, the tip portion of the curve can be completely eliminated.
The vulnerability of the inner hair cell response, however, is a complex phenomenon exhibiting both frequency and intensity dependence and other properties not yet described for the auditory nerve. This study examines some of the frequency and intensity dependent changes of inner hair cell performance during transient asphyxia and characterizes the time course of intracellular potential alterations. It is possible to correlate some of these observations to the decline and recovery of the endocochlear potential (EP) which occurs during asphyxia. The dependence of the changes on frequency lead to a specific dynamic pattern of FTC alteration where there can be some independence of sensitivity and frequency selectivity.

\section{Methods}

Pigmented and albino guinea pigs with body weights between 200 and $350 \mathrm{~g}$ were anesthetized with sodium pentobarbital ( $15 \mathrm{mg} / \mathrm{kg}$ i.p.) and Innovar-Vet $(0.4 \mathrm{ml} / \mathrm{kg}$ i.m. $)$ and paralyzed with curare (0.3 mg i.m.). Artificial respiration was 
provided with continuous monitoring of end-respiratory $\mathrm{CO}_{2}$ and heart rate. A heating blanket maintained rectal temperature at approximately $38^{\circ} \mathrm{C}$ and supplemental heating to the head was provided to maintain normal cochlear temperature [6]. After exposing the cochlea by a ventral-postauricular surgical dissection, a small fenestra was made into scala tympani of the basal turn similar to that described by Sellick and Russell [42] but with modifications previously outlined [5].

Electrical potentials from the round window were measured with a silver wire electrode relative to a chlorided silver wire ground electrode placed in the neck muscles. Intra- and extracellular potentials were measured using glass micropipettes pulled from fiber-type borosilicate glass $(1.5 \mathrm{~mm}$ OD $0.8 \mathrm{~mm}$ ID) using Sutter Instruments Co. (San Francisco, Calif.) electrode puller (Brown-Flaming type). The electrodes, back-filled with $3 \mathrm{M}$ potassium chloride, had resistance values between 50 and $150 \mathrm{~m} \Omega$ and were not beveled. A hydraulic microdrive and a piezoelectric pusher were used to advance the electrodes. Experiments were carried out on a vibration-isolation table within a soundand electrically-shielded booth. High frequency sound stimuli $(2-40 \mathrm{kHz})$ were produced by a $1 / 2$-inch condenser microphone system patterned after a design by Evans [13]. Low frequency (100 Hz) stimuli were produced by a loudspeaker-type driver which was also coupled closed-field to the external ear canal in parallel with the high frequency source. Sound pressures were measured close to the tympanic membrane with the aid of a calibrated probe tube attached to a second 1/2inch condenser microphone. In this report sound pressure levels (SPLs) in $\mathrm{dB}$ are referenced to $20 \times 10^{-6} \mathrm{~Pa}$. Tone bursts with rise-fall times of 1 $\mathrm{ms}$, durations of $10 \mathrm{~ms}$ and repeated at $5-10 / \mathrm{s}$ were used to evoke the compound action potential (CAP) recorded from the round window. Tone bursts with rise-fall times of $10 \mathrm{~ms}$, durations $80-120 \mathrm{~ms}$, and repeated at $5-10 / \mathrm{s}$ were used when testing the response of a hair cell.

Electrode signals were amplified by a capacity compensated DC preamplifier. CAP was measured from an oscilloscope while intracellular DC receptor potential magnitudes were measured with the aid of a laboratory minicomputer after appropriate analog to digital conversion. Both re- sponses were simultaneously recorded on chart paper. $\mathrm{AC}$ receptor potentials and the cochlear microphonic (CM) were measured using a wave analyzer. Round window CAP visual thresholds corresponded to approximately $10 \mu \mathrm{V}$ of peak signal (the $N_{1}$ component).

CAPs to various frequencies between 4 and 40 $\mathrm{kHz}$ were tested to assess surgical or other damage to the cochlea. Most data in this report are from cochleas which were unchanged or were within 10 $\mathrm{dB}$ of normal thresholds between 12 and $20 \mathrm{kHz}$, the typical responsive range of an inner hair cell from the recorded region of the cochlea. 'Insensitive' IHCs of this report were recorded from cochleas with $25 \mathrm{~dB}$ or greater loss of CAP threshold at $20 \mathrm{kHz}$.

A cell was classified as an inner hair cell at the time of recording according to criteria outlined previously [5] and by the appearance of a large DC receptor potential in response to tone bursts as the electrode penetrated the cell [17,37].

Asphyxia was produced by interruption of artificial respiration, usually for periods of 30 or $45 \mathrm{~s}$. For some animals respired with $5 \% \mathrm{CO}_{2}$ and 95\% $\mathrm{O}_{2}$ (carbogen), the duration of the asphyxia was variable; respiration was resumed at the time that heart rate suddenly decreased by approximately one half. One additional guinea pig received pure nitrogen respiration instead of asphyxia, i.e. respiration was maintained but the gas was changed from air to nitrogen. In this case the durations of the anoxia were also 30 and $45 \mathrm{~s}$.

Since all variables could not be recorded simultaneously, any given animal was subjected to more than one asphyxia per experiment. The time course of the decrease in the EP was always measured last in order to avoid electrode penetration through the organ of Corti until after hair cell responses had been measured. Data for FTCs were obtained from a sequence of automatically presented tone bursts. To characterize a cell's full FTC, a set of 12 frequencies spaced approximately $1.5 \mathrm{kHz}$ apart between 6 and $24 \mathrm{kHz}$ was given at 8 sound pressure levels. The 8 intensity levels covered a dynamic range of $64 \mathrm{~dB}$ and the maximum sound level was usually between 85 and $95 \mathrm{~dB}$ SPL. On occasion, detailed DC receptor potential versus SPL (intensity) functions at a single frequency were generated by a sequence of sixteen $5 \mathrm{~dB}$ steps 
(85-95 dB SPL max for sensitive cells) presented in order of decreasing intensity. No effect of order was observed in independent tests. The FTC was usually constructed by extrapolating or interpolating the SPL required to produce $2 \mathrm{mV}$ of $\mathrm{DC}$ receptor potential. During an asphyxia, however, for some inner hair cells, the number of frequencies was reduced to 5 which were centered about the cell's characteristic frequency (CF). FTCs constructed from such data show only the tip portion of the tuning curve. The use of only 5 frequencies allowed a reduction in the time required to generate the FTC data. A 5 frequency FTC was generated every 5-6s.

For experiments which examined the relationship of the AC and DC receptor potentials at the CF during asphyxia, a repeating train of 16 (approximately $100 \mathrm{~ms}$ duration) tone bursts spaced 5 $\mathrm{dB}$ apart were used as above for generating detailed intensity functions. This permitted construction of a sequence of intensity functions for the hair cell during and after the asphyxia. The $\mathrm{AC}$ receptor potential was recorded with a wave analyzer at a bandwidth setting of $100 \mathrm{~Hz}$. Electrodes were capacity compensated subjectively using cues based on the shape of an injected square wave and on the background noise. Only the relative values of $\mathrm{AC}$ potential are meaningful as cell and electrode time constants were not determined.

\section{Results}

\section{Dynamics of FTC changes with asphyxia}

One of the most profound effects of transient asphyxia on the response of the inner hair cell is the reduction of sound evoked receptor potential for frequencies near the CF of the cell $[5,36]$. For a short asphyxia the tail region of the FTC often exhibits little change while the tip portion can be nearly abolished.

Fig. 1 illustrates FTCs from two example inner hair cells where the number of frequencies was minimized and the presentation rate of successive tones was maximized, allowing construction of many FTCs during and following a short asphyxia. In most instances 5 frequencies were chosen centered approximately about the CF of the cell with a distance between the frequencies of 1.5

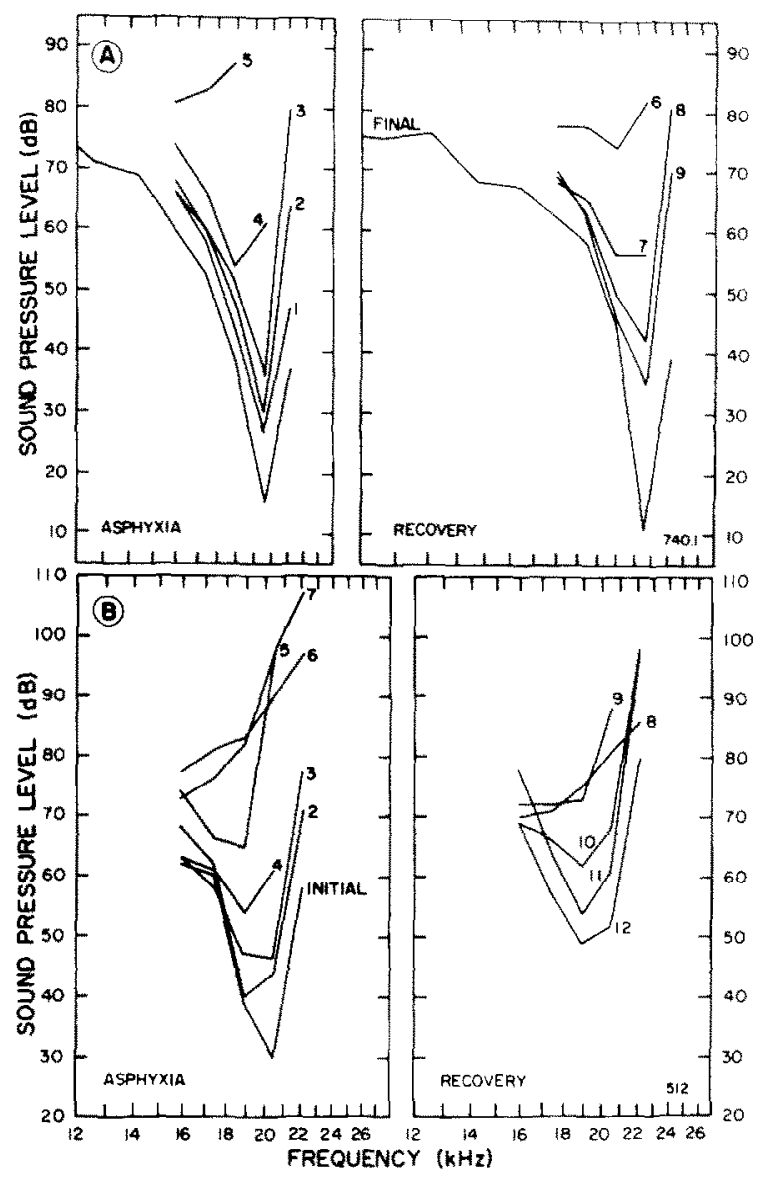

Fig. 1. Frequency tuning curves ( $2 \mathrm{mV}$ FTCs) obtained from two IHCs during and immediately following transient asphyxia. Initial and final FTC's taken before and after asphyxia respectively are labeled. For the cell of (A) a 12 frequency FTC was obtained before and after a $70 \mathrm{~s}$ asphyxia following carbogen breathing. All other FTCs, of both cells, were interpolated from intensity functions generated by five frequencies. The parameter is the sequence order of the FTC. Each 5 frequency FTC required 5-6 s of tone presentations. For the cell of (B), data collection was terminated before the cell fully recovered from a $30 \mathrm{~s}$ asphyxia giving a degraded 'final' FTC. These graphs show the accumulation and recovery from tip sensitivity loss and a downward shift of the characteristic frequency.

$\mathbf{k H z}$. Other experiments used a finer frequency resolution of $0.8 \mathrm{kHz}$. Thus, the resulting FTC frequency range encompassed just a portion of the tip area of the normal FTC curve. For the IHC of Fig. 1A a complete (12 frequency) FTC was also obtained.

The vulnerability of the FTC tip is evident in Fig. 1. There is a progressive and monotonic shift 
TABLE I

THE EFFECT OF TRANSIENT ASPHYXIA ON FTC TIP SENSITIVITY, $Q_{10 \mathrm{~dB}}$ AND CF

The animals were subjected to $30 \mathrm{~s}$ of asphyxia with the following exceptions: No. 689 for $45 \mathrm{~s}$ asphyxia; No. 738 for $30 \mathrm{~s}$ of nitrogen breathing; No. 740 for $30 \mathrm{~s}$ asphyxia after carbogen breathing. The principal finding expressed in this table is that $30 \mathrm{~s}$ of asphyxia leads to approximately a $30-40 \mathrm{~dB}$ loss in FTC tip sensitivity which is accompanied by approximately a $1 / 4$ octave shift downward from the CF. N.A., $Q_{10 \mathrm{~dB}}$ could not be determined.

\begin{tabular}{llcccc}
\hline $\begin{array}{l}\text { Hair } \\
\text { cell } \\
\text { No. }\end{array}$ & CF & $Q_{10 \mathrm{~dB}}$ & $\begin{array}{l}\text { Tip sensitivity } \\
\text { (dB SPL) }\end{array}$ & $\begin{array}{l}\text { Tip sensitivity } \\
\text { decrease (dB) }\end{array}$ & $\begin{array}{l}\text { CF shift } \\
\text { downward } \\
\text { (kHz) (octave) }\end{array}$ \\
\hline 414 & 19.4 & N.A. & 45 & 45 & $>1.5(>0.12)$ \\
420.1 & 20.5 & 7.0 & 4 & 50 & $1.5(0.10)$ \\
512 & 20.5 & 8.5 & 30 & 64 & $>4.7(>0.38)$ \\
554 & 19.9 & 8.0 & 47 & 37 & $>3.0(>0.24)$ \\
605 & 22 & 5.9 & 25 & 29 & $2.6(0.18)$ \\
677 & 17 & N.A. & 32 & $>60$ & $>3.2(>0.30)$ \\
689 & 18.5 & N.A. & 25 & $>45$ & $>1.4(>0.11)$ \\
738 & 19.9 & 13.2 & 22 & 59 & $>3.1(>0.24)$ \\
740 & 21.5 & 11.4 & 28 & $>29$ & $>4.7(>0.36)$ \\
\hline
\end{tabular}

upward toward decreased sensitivity which is followed by a recovery having the reversed pattern. Careful inspection of the figure reveals that the CF in each case shifts toward lower values during the time course of the asphyxia and, later during recovery, progressively returns to the initial value. Measuring the extent of the shift is hampered by the relatively coarse frequency steps and in some cases by the lack of sufficient low frequency points. CF shifts and other parameters for 9 IHCs, measured during various lengths of asphyxia, are given in Table I. CF shifts greater than $1 / 4$ octave towards lower frequencies were a common result of these asphyxias; greater shifts occurred for the longer asphyxias.

In addition to a change in the CF, two other features of the tuning curve tip are used to describe its character. The criterion response $(2 \mathrm{mV}$ of $\mathrm{DC}$ receptor potential in this study) at the CF indicates the sensitivity of the cell while the $Q_{10 \mathrm{~dB}}$ measure describes its sharpness of tuning. $Q_{10 \mathrm{~dB}}$ is defined as the $C F$ frequency divided by the frequency width of the FTC $10 \mathrm{~dB}$ above the tip. $Q_{1 \text { dB }}$ values of this study are interpolations from straight line segments drawn between data points. Fig. 2A shows the decibel change in sound level to evoke the criterion response for 5 IHCs during and following an asphyxic period. The curves show an orderly loss in responsiveness that ranges between
30 and $65 \mathrm{~dB}$. On resumption of respiration there is a recovery of sensitivity that proceeds over a longer time course than the initial decline. $Q_{\text {lod }}$ changes that accompany the tip sensitivity changes are given in Fig. 2B. Note that all of the plotted functions of Fig. 2B are segmented, having an early portion between 0 and $30 \mathrm{~s}$ and a recovery segment later. The hiatus is due to the inability to measure a $Q_{10 \mathrm{~dB}}$ when the FTC is no longer ' $\mathrm{V}$ ' shaped or when the arms of the ' $V$ ' are less than $10 \mathrm{~dB}$ in vertical length (see Figure 1). Although the accuracy of the $Q_{10 \mathrm{~dB}}$ measure is limited by the resolution of the frequency steps used to generate the FTC, there is a clear tendency for the sharpness of tuning to remain constant for a period of time at the beginning of the asphyxia. During this time period the tip sensitivity is decreasing. In general the tip sensitivity may become depressed by $10-20 \mathrm{~dB}$ while the $Q_{10 \mathrm{~dB}}$ remains within one unit of the initial level.

This phenomenon is the result of a differential change in the IHC's response across frequency. Fig. 3 shows, for one IHC, the sound level required to produce the $2 \mathrm{mV}$ criterion response for 4 frequencies at and near the IHC CF. The rate of change of the criterion response is greatest for the highest frequency and somewhat less for each successively lower test frequency. 

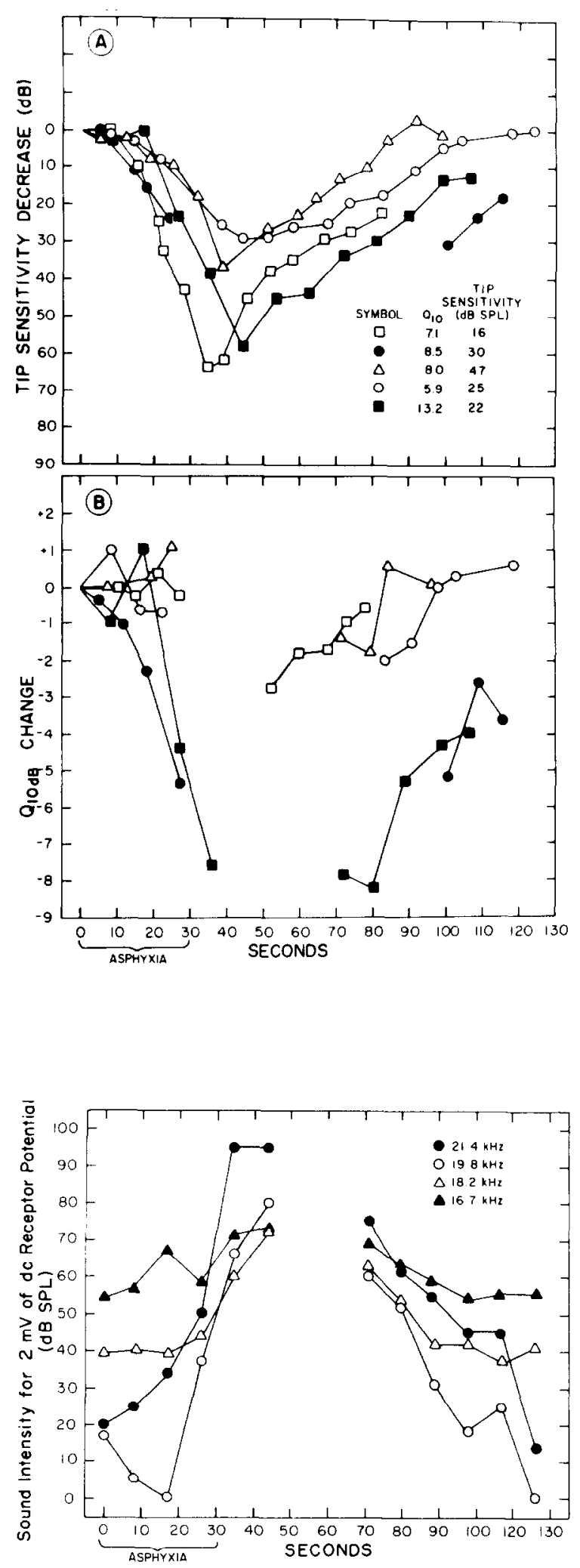

Fig. 2. Changes in $Q_{10 \mathrm{~dB}}$ and FTC tip sensitivity during and following $30 \mathrm{~s}$ asphyxia. (A) The decibel decrease in FTC tip sensitivity for 5 IHCs. The legend gives the initial tip sensitivity. Note also that the filled squares are for an animal respired on nitrogen for $30 \mathrm{~s}$. (B) The change in $Q_{\text {lodB }}$ caused by transient asphyxia. The curves are broken where altered FTC tip configurations did not permit measurements of $Q_{10 \mathrm{~dB}}$. The legend of part A also applies to these curves.

Level dependence of the $D C$ receptor potential changes with asphyxia

Near the characteristic frequency, where the asphyxic effect is most dramatic, there is a pronounced dependence of the changes on the level of the stimulus. Fig. 4 shows examples of intensity functions at $\mathrm{CF}$ from three IHCs taken during the period of asphyxia. In each panel of Fig. 4, the parameter is time measured in seconds. Thus the figure illustrates how the intensity function changes from its normal state, where it exhibits a low level linear segment and a saturation-like segment at high sound pressure levels, to a condition where it has become somewhat straightened. The increased $\mathrm{dB}$ range of the straight segment comes about mostly at the expense of low level performance of the cell.

The time course of level dependence is more easily seen in Fig. 5 which plots the DC receptor potential changes at four sound pressure levels (from two IHCs) during two asphyxia durations (30 and $45 \mathrm{~s}$ ) and during recovery. DC receptor potentials evoked by the low level sounds in this figure are greatly reduced and require long time periods to recover. In contrast, the $\mathrm{DC}$ receptor potentials evoked by the highest level sound ( 94 dB SPL) follow a time course which bears considerable similarity to that of the endocochlear potential which is also plotted in Fig. 5.

These level dependent effects apply in an orderly fashion to the frequency dependent effects described above. Fig. 6 plots the percentage change of the DC receptor potential for 4 frequencies (same IHC as Fig. 4B). Once again the more profound influence is for the low SPLs (Fig. 6A)

Fig. 3. Change in the sound pressure level to evoke a $2 \mathrm{mV}$ criterion response of $D C$ receptor potential at 4 frequencies (CF was $19.8 \mathrm{kHz}$ ). The rate of change is seen here to be related to frequency of stimulation. The dip in the function for $19.8 \mathrm{kHz}$ between 0 and $20 \mathrm{~s}$ is due to measurement variability and is not a consistent finding. 


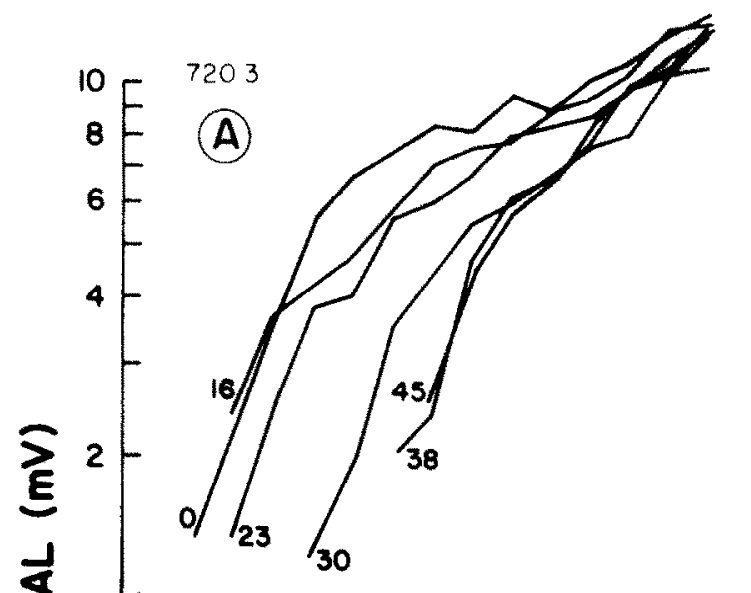

F

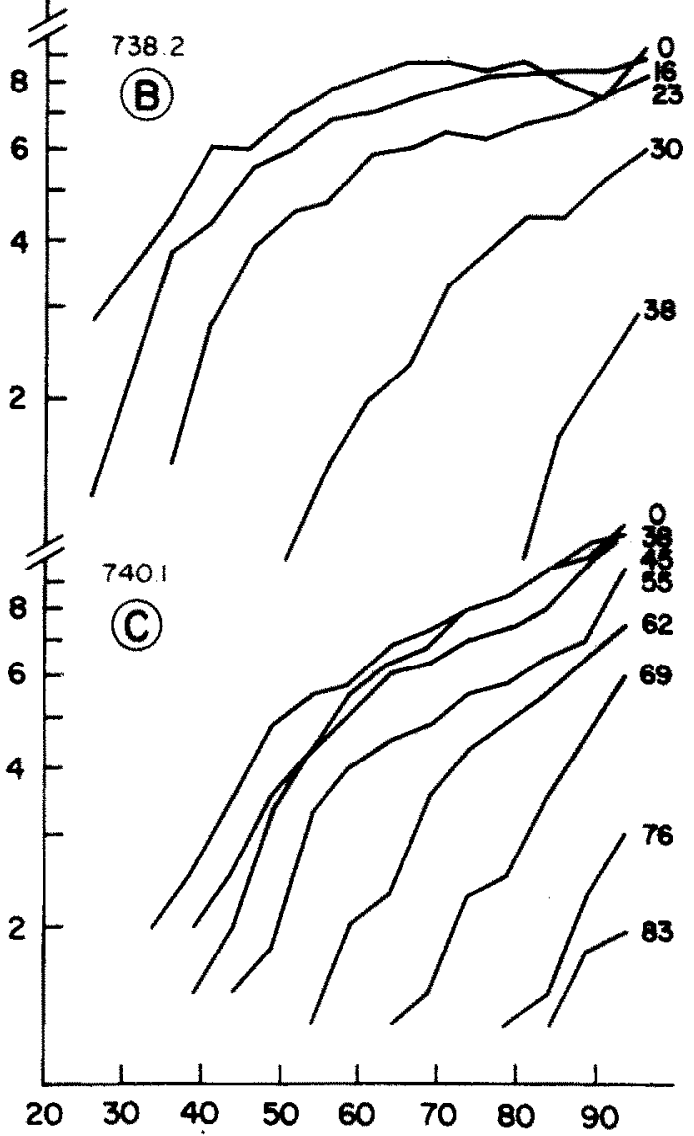

\section{SOUND PRESSURE LEVEL (dB)}

Fig. 4. Intensity functions at $\mathrm{CF}$ for three IHCs taken at various times during the accumulating performance loss caused by asphyxia. The parameter is seconds from the start of asphyxia. (A) the guinea pig received $30 \mathrm{~s}$ asphyxia after air respiration; (B) $30 \mathrm{~s}$ anoxia with nitrogen respiration; (C) $70 \mathrm{~s}$ asphyxia after carbogen respiration. but the functions are also ordered in frequency. The asphyxia caused greater reduction for increasing frequency.

The data of Figs. 5 and 6 and from other hair cells of this study can be summarized as follows: (1) transient asphyxia produces a sensitivity shift in the inner hair cell that is qualitatively similar to the time course of the endocochlear potential change when the cell is excited by low ('tail') frequencies (at all sound levels) or by high ("tip") frequencies presented at high sound levels; (2) for high frequencies presented at low levels, the sensitivity of the inner hair cell response is more reduced and has a longer recovery time course than the EP. In the second case the effect of asphyxia is monotonically ordered with frequency, asphyxia having a greater influence with increasing frequency.

Intensity function slope changes with asphyxia

It is of theoretical concern to know the slope of the linear portion of IHC input-output (intensity) functions before and during asphyxia. The slope of

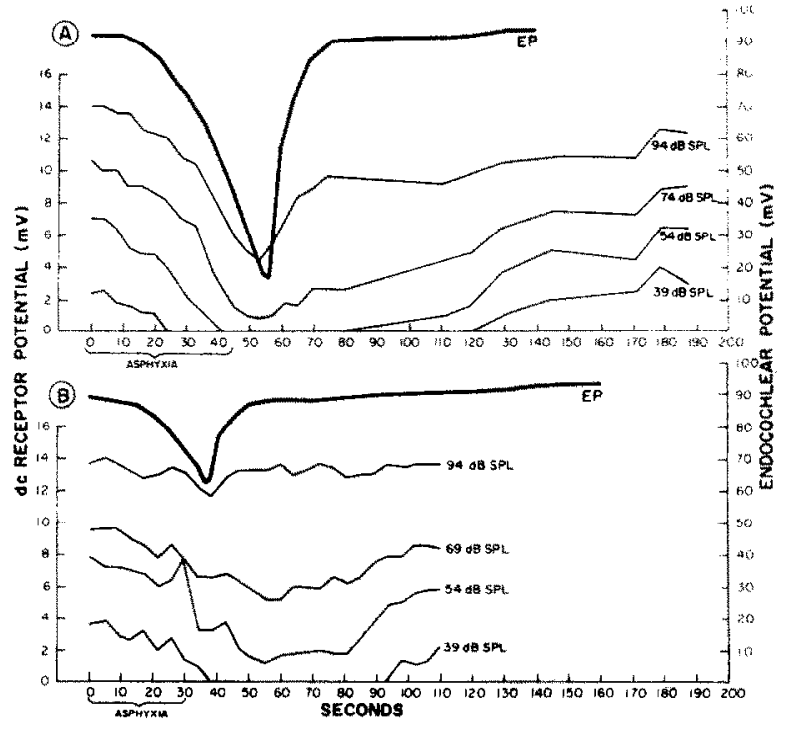

Fig. 5. Effect of asphyxia on the magnitude of the DC receptor potential at CF for two IHCs and on the endocochlear potential (EP). The parameter is sound pressure level. For the upper panel a $45 \mathrm{~s}$ asphyxia was administered and for the lower a $30 \mathrm{~s}$ asphyxia. The recovery of IHC performance is seen to be level dependent and takes on the shape of the EP change for high sound levels. Note that the EP and DC receptor potential data are from separate asphyxias. 


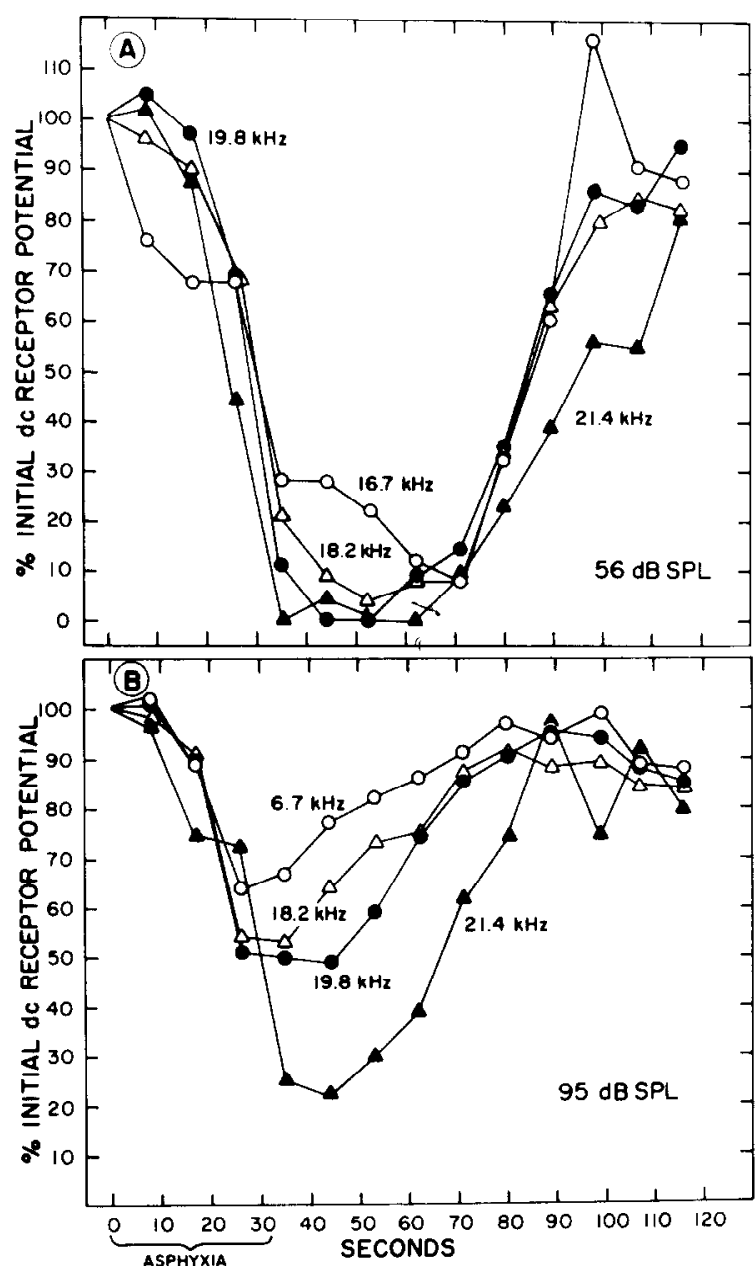

Fig. 6. Effect of $30 \mathrm{~s}$ transient asphyxia on the magnitude of the DC receptor potential plotted as percentage change. The parameter is frequency and cell CF was $19.8 \mathrm{kHz}$. (A) Each frequency was presented at $56 \mathrm{~dB}$ SPL. The $100 \%$ level was: 2.5 $\mathrm{mV}$ for $16.7 \mathrm{kI} \mathrm{Iz} ; 7.8 \mathrm{mV}$ for $18.6 \mathrm{kHz} ; 8.8 \mathrm{mV}$ for $19.8 \mathrm{kHz}$; and $6.2 \mathrm{mV}$ for $21.4 \mathrm{kHz}$. (B) Each frequency was presented at $95 \mathrm{~dB}$ SPL. The $100 \%$ level was $12.5 \mathrm{mV}$ for $16.7 \mathrm{kHz} ; 12.9 \mathrm{mV}$ for $18.6 \mathrm{kHz}$; $10.8 \mathrm{mV}$ for $19.8 \mathrm{kHz}$; and $7.6 \mathrm{mV}$ for $21.4 \mathrm{kHz}$.

the guinea pig DC receptor potential intensity function for the IHC was first described as being linear with sound pressure [37], but in the gerbil for frequencies at or below $\mathrm{CF}$ it was proportional to sound intensity (i.e., DC receptor potential grew as the square of sound pressure) [17]. Recently Patuzzi and Sellick [31] confirmed that this is also the case for the guinea pig. In the present study 11 sensitive and 2 insensitive IHCs were examined for the intensity function slopes at $C F$ and for frequencies in tail area.

The results of this analysis are given in Table II along with other parameters which characterize the cells. The slopes were determined qualitatively by observing which slope ( 1 or $2 \mathrm{~dB}$ of receptor potential per $\mathrm{dB}$ of sound pressure) best fits the linear portion of the function. For 'tail' frequencies the slope is approximately $2 \mathrm{~dB} / \mathrm{dB}$ in concurrence with the intensity-linearity found by Goodman et al. [17] and Patuzzi and Sellick [31]. At the CF the slopes in Table 2 tend to be less than 2 $\mathrm{dB} / \mathrm{dB}$ but two factors could influence this result and lead to an artificially low slope estimate. Firstly, intensity function slopes decline for frequencies greater than CF $[17,31,37]$, and due to the frequency resolution of this experiment, some of the data may be for frequencies slightly above CF. Also, Patuzzi and Sellick [31] note that the highest slopes (at CF) occurred for the very low sound levels which generated DC receptor potentials below $1 \mathrm{mV}$. Since the noise floor of the present study was approximately $0.4 \mathrm{mV}$, the high slopes, where potentials are small, could be missed. The finding of four IHCs with intensity function slopes at CF greater than 1 tends to support an intensity-linear model.

It is evident that the intensity functions of Fig. 4 become abnormal during asphyxia. In addition to the straightening that occurs, as mentioned above, there is a change in the slope of the low level portion of the curves. Table III presents the results of an analysis of families of intensity functions such as those of Fig. 4 for slope change during asphyxia. All of the measured IHCs evidenced a decreased slope of the intensity function at original $\mathrm{CF}$ during asphyxia; the minimum slope was approximately $0.5 \mathrm{~dB} / \mathrm{dB}$. They fully recovered to preasphyxic values upon resumption of respiration.

The observation of declining slopes is a predictable result of the measurement method because the nominal $C F$ is not tracked during asphyxia. Thus as an IHC CF shifts downward, the constant frequency stimulus at original CF gradually becomes an above nominal-CF stimulus where intensity function slopes for normal IHCs are lower. One interpretation of the results is that an IHC with shifted $\mathrm{C} F$ during early asphyxia, is less 
TABLE II

ANALYSIS OF CF AND TAIL FREQUENCY INTENSITY FUNCTION SLOPES FOR THE DC AND AC RECEPTOR POTENTIALS OF $13 \mathrm{IHCS}$

The slopes are a graphical qualitative measure of best fit $(1$ or $2 \mathrm{~dB} / \mathrm{dB})$ to the linear portion of the intensity function when plotted as $\log$ DC receptor potential for linear $\mathrm{dB}$ SPL. Thus a slope of 1 indicates a linear growth of response with sound pressure, while a slope of 2 indicates a linear growth of response for sound power (SPL). Dynamic range is a qualitative estimate of the length of the linear portion of the DC receptor potential intensity function from $1 \mathrm{mV}$ to an obvious start of saturation. $E_{m}$ is resting membrane potential. N.A., the value could not be determined.

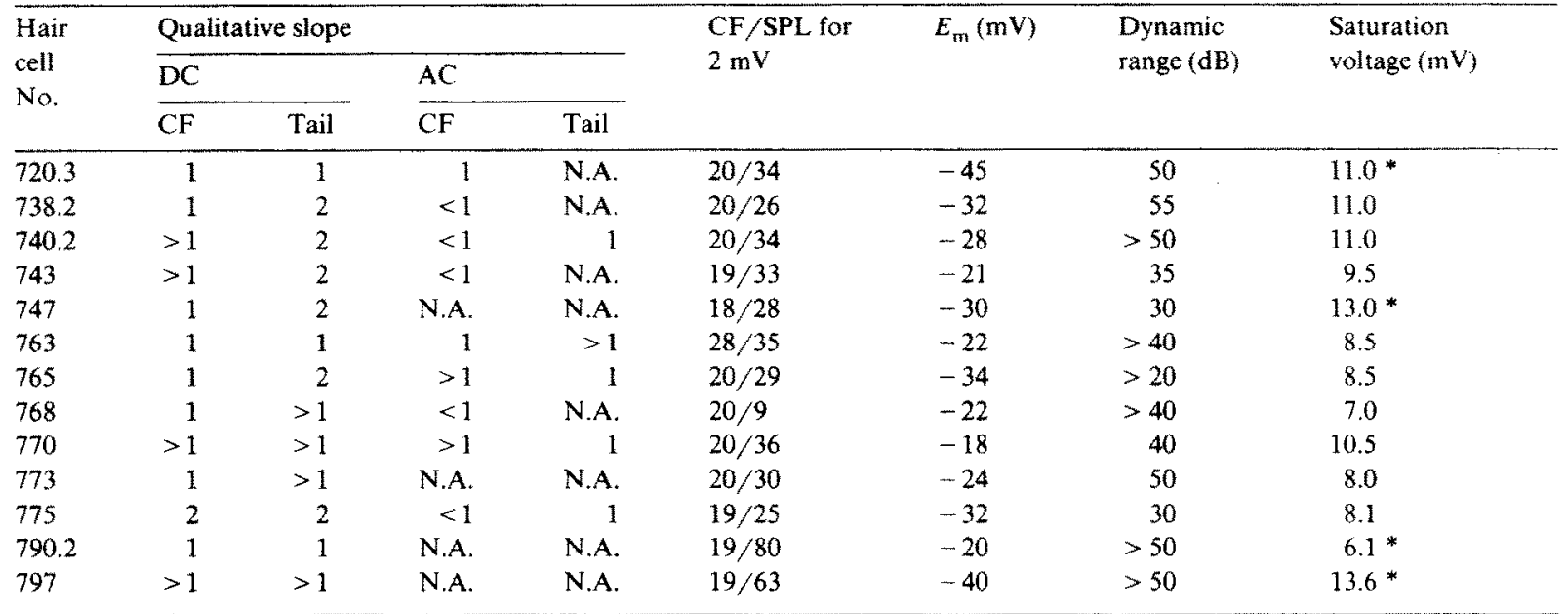

* The function did not have a distinct saturation for the sound levels presented. Cells 790.2 and 797 are considered to be 'insensitive'.

sensitive but 'normal' with regard to growth of its response with sound level. However, an inspection of the functions of Fig. 4 in comparison to above CF intensity functions in nonasphyxic IHCs
$[17,31,37]$ reveals that, under asphyxia, they have an abnormally wide dynamic range and high saturation levels.

TABLE III

\section{AN ANALYSIS OF DC RECEPTOR POTENTIAL SLOPE CHANGES OF THE LINEAR PORTION OF CF INTENSITY FUNCTIONS FOR THE DC RECEPTOR POTENTIAL DURING TRANSIENT ASPHYXIA}

The slopes are: $\mathrm{dB}$ of $\mathrm{DC}$ receptor potential divided by $\mathrm{dB}$ SPL and obtained by linear regression. The slope at 'initial" is the preasphyxic value while 'recovery' is that obtained one to several minutes after resumption of respiration.

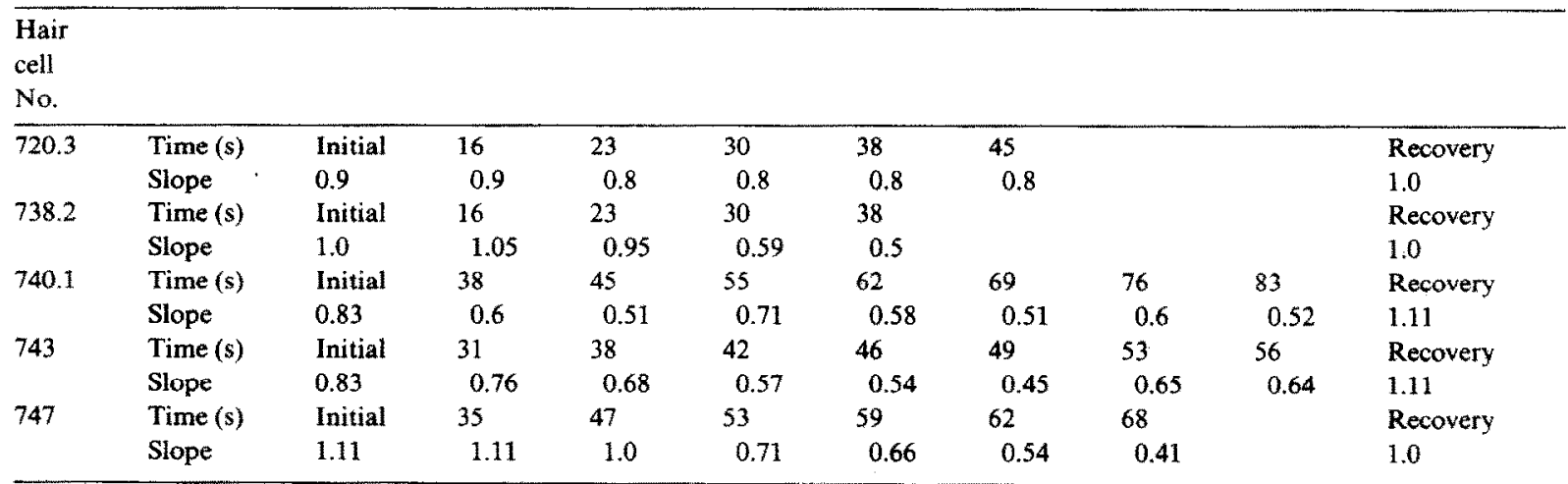


Relationship between the $D C$ and the $A C$ receptor potential at $C F$ during asphyxia

The $\mathrm{AC}$ receptor potentials which can be recorded from inner hair cells are very much attenuated by the electrical filtering of the inner hair cell membrane and the microelectrode [37]. Nonetheless $\mathrm{AC}$ potentials (at $\mathrm{CF}$ ) which are approximately $1 / 1000$ of the DC receptor potential magnitude can be obtained and their relative changes (at a particular frequency) are useful. For any given frequency both the $\mathrm{AC}$ and the $\mathrm{DC}$ receptor potentials are reduced by asphyxia. In order to compare the change of the two potentials the ratio of the $A C$ receptor potential to the $D C$ was computed. AC-DC ratios are plotted in Fig. 7 for four example hair cells and each panel shows the ratio at 4 to 6 sound levels from approximately 40 to 96 UB SPL. The stimulus frequency was always at the characteristic frequency of the IHC. Gaps in the functions represent areas where the signal levels
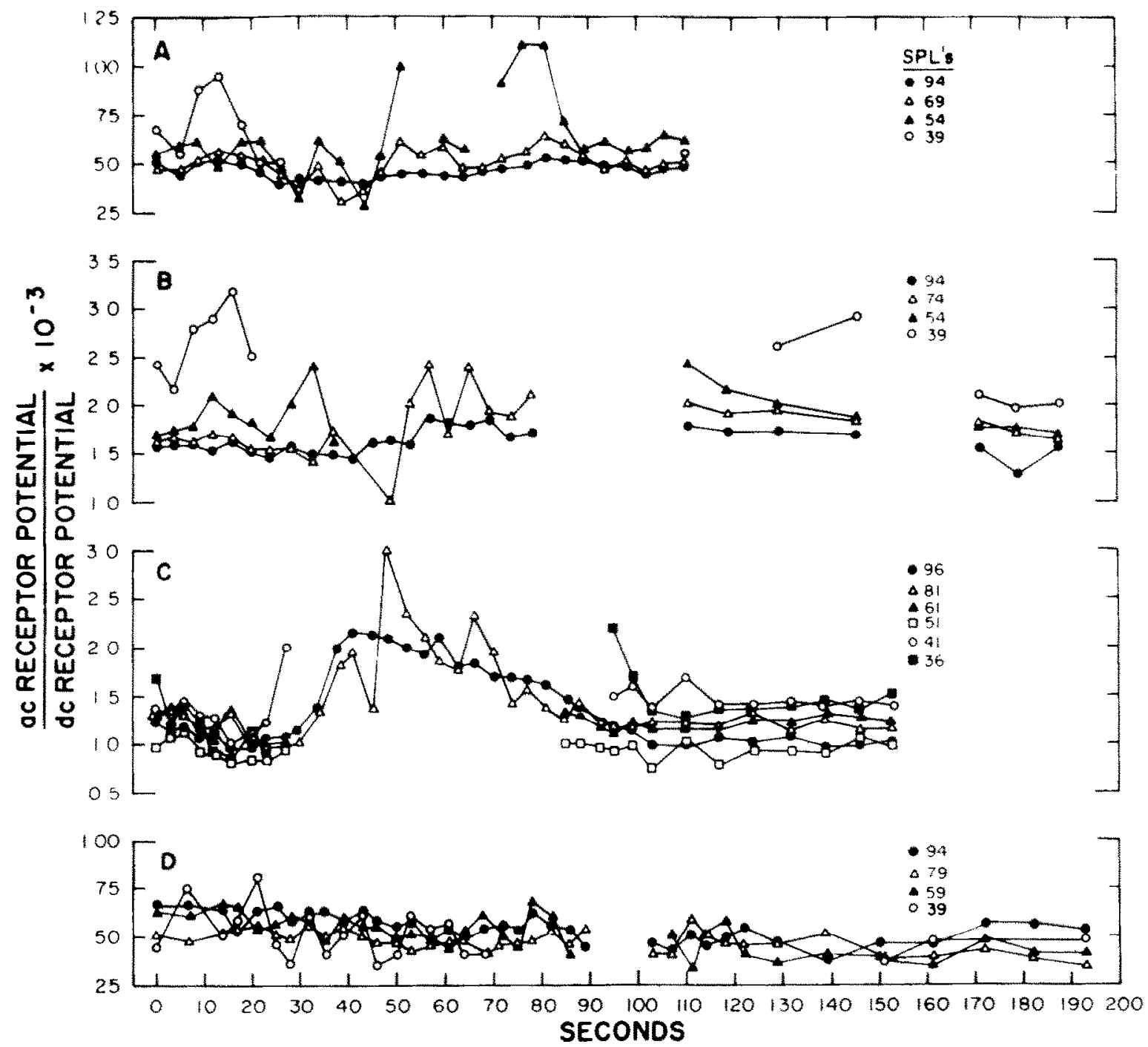

Fig. 7. The ratio of the AC receptor potential to the DC receptor potential during transient asphyxia for 4 IHCs. Broken curves represent inability to calculate the ratio due to unmeasurably low potential values. The parameter is sound pressure level. Cells of $A$ and $\mathrm{B}$ were subjected to $30 \mathrm{~s}$ asphyxias; Cell $\mathrm{C}, 30 \mathrm{~s}$ of nitrogen respiration; $\mathrm{Cell} \mathrm{D}, 70 \mathrm{~s}$ of asphyxia after carbogen respiration. In general, the ratio is not changed during asphyxia. The changes for Cell $\mathrm{C}$ are possibly artifactual (see text). 
became unmeasurable (approximately $0.5 \mathrm{mV}$ for the DC receptor potential and $1 \mu \mathrm{V}$ rms for the $\mathrm{AC}$ receptor potential).

For the most part the graphs illustrate that the $A C$ and $D C$ receptor potentials are equally affected during the asphyxia and that there is no significant level dependent effect. The results from the cell of Fig. $7 \mathrm{C}$ are an exception since small but systematic increases in the ratio occurred at all levels of stimulation. For seven inner hair cells where the ratio has been carefully investigated at the $\mathrm{CF}$, only one cell showed a slight increase in the ratio. The change for the cell of part C (Fig. 7) is possibly an artifact caused by variable cell impalement during asphyxia. For two other hair cells where ratios could be computed for only high level stimuli (>50 dB SPL) there were also no significant increases in the ratio.

The measurement of AC receptor potentials is technically difficult and subject to errors due to uncertainties about cell and electrode capacitance properties. Additionally, there is the theoretical possibility of contamination of the intracellular signal by cochlear microphonic. The $\mathrm{CM}$ is a rather large signal which could be electrically conducted to the intracellular site or electrically coupled through the wall of the electrode. Thus it is of interest to examine the time course and magnitude shift of the extracellular signals as well. Fig. 8 compares the $\mathrm{AC}$ receptor potential (at $\mathrm{CF}$ for 5 sound pressure levels) in an IHC to $\mathrm{CM}$ in the organ of Corti near the IHC during and after a 30 $s$ asphyxia. In both panels it is obvious that, as for the DC receptor potentials, there is a sound level dependence. Low sound level responses are more greatly depressed during asphyxia and they require a longer time period to recover. However, the intracellular signals are more strongly influenced by the asphyxia than are the extracellular signals. Consequently, although the intracellular AC receptor potential was larger than the extracellular at the start of asphyxia, this situation reversed during the time of maximum change. The implication is that intracellular AC potential in this hair cell does not have an important extracellular $\mathrm{CM}$ component.

The low frequency response $(100 \mathrm{~Hz})$ of three IHCs was measured during asphyxia to determine if the wave shape changed from a rectified to a

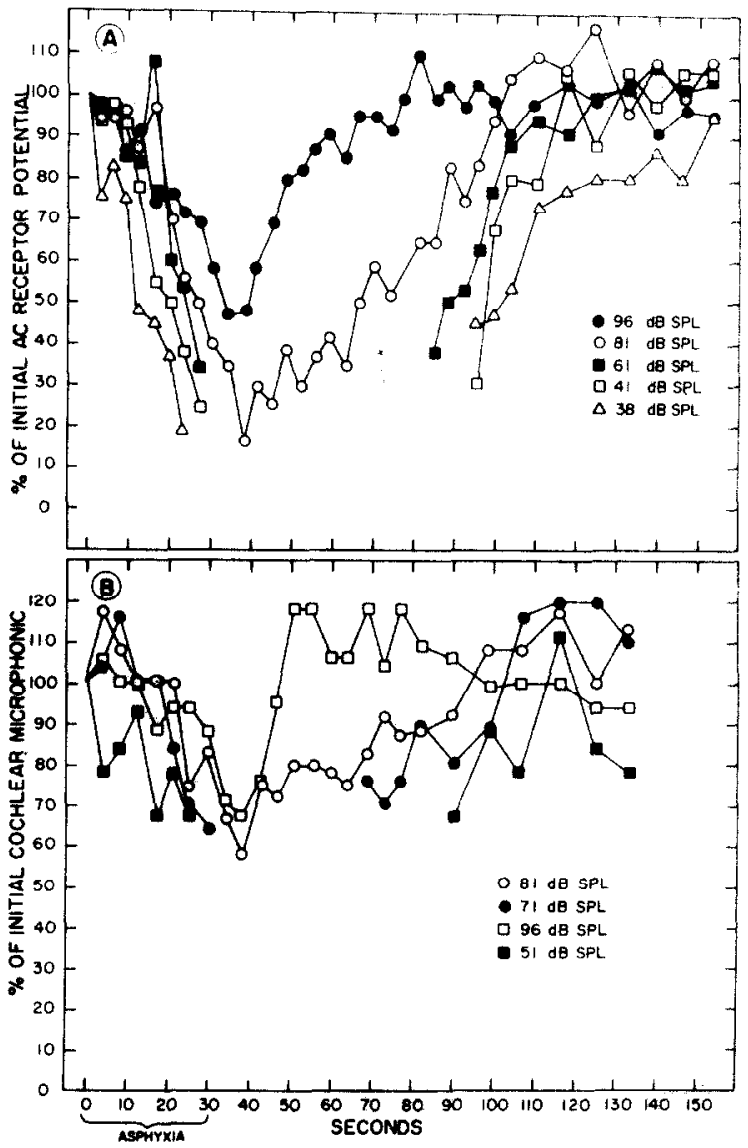

Fig. 8. The percentage change of the $\mathrm{AC}$ receptor potential at CF (A) compared to the percentage change of the extracellularly recorded cochlear microphonic (B) near the electrode position of (A). The parameter is sound pressure level and this cell performance change was observed for $30 \mathrm{~s}$ of nitrogen breathing. In (A) the 100\% levels were: $11.6 \mu \mathrm{V}$ for $96 \mathrm{~dB}$ SPL; $9.7 \mu \mathrm{V}$ for $81 \mathrm{~dB}$ SPL; $7.1 \mu \mathrm{V}$ for $61 \mathrm{~dB}$ SPL; $5 \mu \mathrm{V}$ for $41 \mathrm{~dB}$ SPL: and $44 \mu \mathrm{V}$ for $36 \mathrm{~dB}$ SPL. In (B) the $100 \%$ levels were: 8.5 $\mu \mathrm{V}$ for $96 \mathrm{~dB}$ SPL; $7.1 \mu \mathrm{V}$ for $81 \mathrm{~dB}$ SPL; $6.3 \mu \mathrm{V}$ for $71 \mathrm{~dB}$ SPL; and $4.5 \mu \mathrm{V}$ for $51 \mathrm{~dB}$ SPL.

non-rectified form as described by Russell and Cowley [36]. In response to $105 \mathrm{~dB}$ SPL sinusoidal stimulation at $100 \mathrm{~Hz}$, inner hair cells produced asymmetric waveforms of approximately $10 \mathrm{mV}$ $p-p$ having a pronounced rectification in the depolarizing direction. During asphyxia this waveform changed to one having a more sinusoidal shape without a DC component. This confirms the earlier observation [36] that at very low frequencies $(100 \mathrm{~Hz})$ the intracellular $\mathrm{AC}$ receptor poten- 
tial is more resistant to asphyxia than is the DC receptor potential. The resulting $A C / D C$ ratio in this case would increase during asphyxia. At the present time the reasons for the differences found for the $A C / D C$ ratio at $C F$ between present and our previous results [6] and those of the Russell and Cowley [36] study remain obscure.

\section{Relationship of endocochlear potential changes to} IHC membrane potential changes during asphyxia

The dramatic fall in the magnitude of EP during asphyxia is usually accompanied by change in the resting membrane potential of the inner hair cell $[5,36]$. The functions sometimes parallel one another quite closely as seen for the IHCs of Fig. 9. The membrane potential changes in these instances were well ordered and highly correlated with the EP changes, but cell recovery is some-

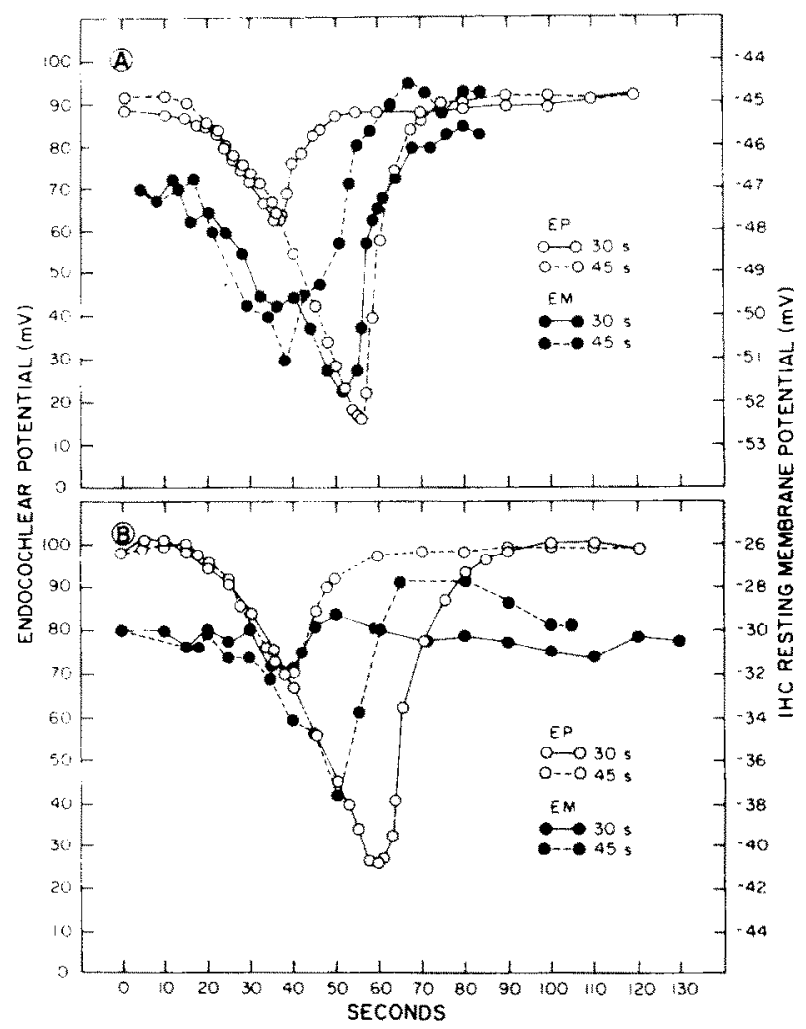

Fig. 9. Changes in the resting membrane potentials $\left(E_{\mathrm{m}}\right)$ of IHCs compared to the corresponding EP changes of similar duration asphyxias but obtained after the IHC measures. (A) Asphyxias of 30 and $45 \mathrm{~s}$ duration from two IHCs of the same animal (B) Asphyxias of 30 and 45 s duration obtained successively from one IHC. times incomplete, as in Fig. 9A. The resting membrane potentials of some hair cells were less well correlated to EP change, but hair cells exhibiting the good correlation of Figs. 9A and B were more common, as is the observed transient depolarization during recovery (Fig. 9B).

The relationship between the EP and the IHC resting potential, illustrated by Fig. 10, demonstrates the changes induced by asphyxia for ten IHCs where a well defined change in membrane potential occurred during asphyxia. The relationship shown is for the falling portion of curves (i.e. during the actual period of asphyxia). Variability in these data is partially due to nonsimultaneous measurement of $E_{\mathrm{m}}$ and EP. It is evident that for any particular IHC there is a reasonably linear relationship between the potentials. Linear regression lines were fit to each of these functions and the average slope was 0.10 and the average correlation coefficient $(r)$ was 0.94 .

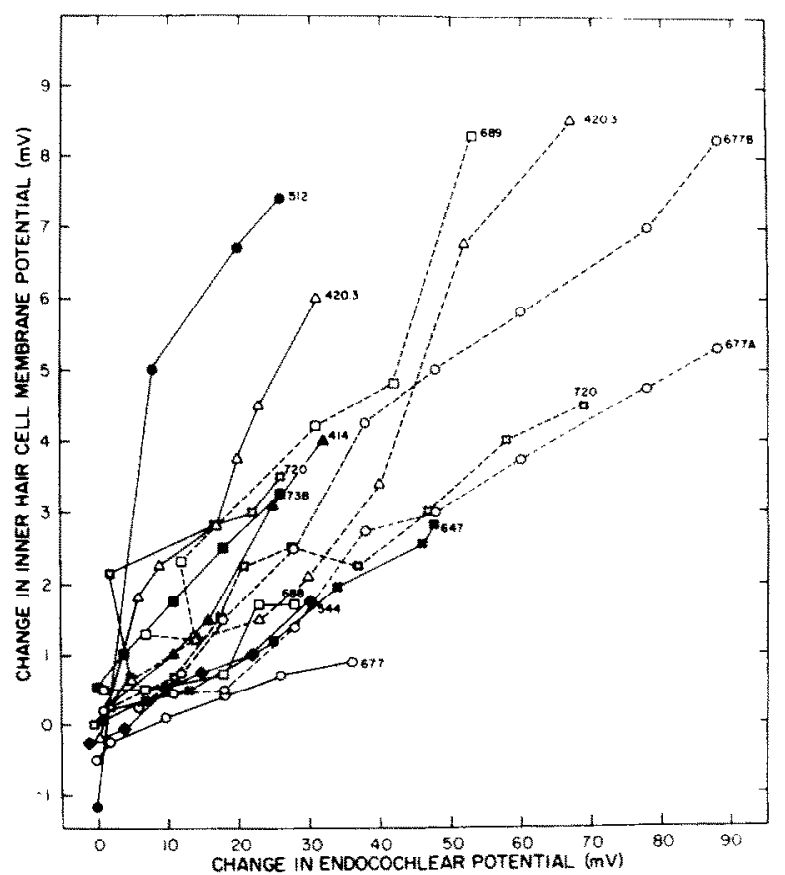

Fig. 10. The relationship between the millivolt change of the endocochlear potential and the millivolt change of the IHC resting membrane potential for $30 \mathrm{~s}$ asphyxias ( - $\longrightarrow$ ) and 45 $s$ asphyxias (- - - ) A and $B$ designations are repeated asphyxias in the same cell. The data are for the declining portion of the EP change during asphyxia. 


\section{Discussion}

Asphyxia is a useful tool for studying cochlear hair cells in an abnormal but controlled condition. Since the physiological condition associated with asphyxia (hypoxia, pH change, etc.) can be established quickly, it is possible to measure the performance of hair cells for both the normal and asphyxic conditions in the several minutes that typifies an intracellular recording period. Recovery from asphyxia is also rapid, offering an opportunity to verify that recording conditions have not changed.

The present study reports that IHC performance undergoes a progressive and complex change during asphyxia. For low intensity stimuli of frequencies in the sharply tuned response area of the cell, there is an ordered frequency-specific loss in sensitivity of the IHC. This results first in a change in the sensitivity of the tip portion of the FTC without significant loss in sharpness of tuning. In fact, the high frequency slope of the FTC may increase, leading to an increase in $Q_{10 \mathrm{~dB}}$ (see Fig. 2A). As a consequence, the loss of criterion sensitivity $(2 \mathrm{mV})$ is also ordered in frequency and there is a progressive downward shift of the CF. Some of these findings for the IHC also have been observed in the auditory nerve for various noxious conditions. A decreased sensitivity of auditory nerve fibers without accompanying loss of sharp tuning has been reported by Harrison and Evans [18] for cochleas having drug-damaged outer hair cells. It should be noted, however, that in studies of auditory nerve tuning during anoxia $[11,14]$ and asphyxia [35], sensitivity loss was always accompanied by frequency selectivity changes. The discrepancy between these data and the findings of the present study could be interpreted as evidence that cochlear hypoxia had an additional influence on the neuron. However, it is more likely that the effect was not observed in the neural studies because of the length of time required to collect spike data for frequency threshold curves. During that time the accumulating effects of asphyxia could cause cell performance to pass through the intermediate stage where sensitivity and frequency selectivity are independent. The CF shift observed in the present study supports the hypothesis that damaged auditory neurons are tuned to frequen- cies below their normal values [20,24,39].

At high sound levels, for tip frequencies, and at all sound levels for tail frequencies, the time course of DC receptor potential change has the shape of the change in the endocochlear potential. Under these conditions this implies that the sensitivity of the IHC is proportional to EP as would be predicted by the hair cell transduction model proposed by Davis [9]. In contrast, low sound level responses of the tip frequencies have a more complex time course of change during asphyxia. A second process must be proposed to act in addition to and/or as result of EP change for these low level tip frequency stimuli. If the second process is an outer hair cell mediated mechanical gain as implied by results from experiments which stimulated the crossed olivocochlear bundle [4], then models which describe this phenomenon must address the frequency dependent changes in II IC tuning which can be observed with asphyxia.

A mechanical role for the outer hair cells in affecting basilar membrane vibration is one hypothesis which could account for changes in inner hair cell responsiveness for near $\mathrm{CF}$ frequencies. The observations of Rhode [34] concerning physiologically vulnerable nonlinear basilar membrane vibration in the monkey, which have also been shown for the guinea pig [43], are possibly related to the asphyxia induced effects. In addition, Patuzzi et al. [32] have demonstrated that the nonlinear intensity function of basilar membrane motion (velocity) is vulnerable to loud sound. Temporary sound-induced changes in the intensity function bear resemblance to those reported above for asphyxia.

The findings of this study show that the inner hair cell resting membrane potential changes during asphyxia are correlated with EP changes. This implies that the intracellular resting potential of the IHC is modified by a standing (steady state) receptor current which is proportional to the endocochlear potential. The constant of proportionality (0.1) can be interpreted as representing the ratio of the hair cell basal resistance to the series combination of the basal and apical hair cell resistances. Thus, the apical resistance must be approximately 10 times that of the basal resistance of the IHC. The ratio of 0.1 is similar to but higher than the theoretical value (approx. 0.03) which can be 
calculated from the known values of the intracellular resting potential and the EP [8]. It is consistent also with other indirect measures based on the distribution of $\mathrm{CM}[50]$ and on cochlear electroanatomy (e.g., see [48]).

Precisely how the asphyxic condition causes the changes in IHC activity is a matter of conjecture at this time. Even the short duration asphyxias of this study lead to a complex set of physiologic responses on both the systemic level and within the cochlea. Asphyxia causes a drop in the amount of oxygen (hypoxia) within perilymph and endolymph $[22,25,33]$ and undoubtedly this oxygen debt would compromise the performance of cochlear tissues which are particularly heavy oxygen users. Thus the stria vascularis, an area demonstrated to have high aerobic metabolism, may be more vulnerable than the organ of Corti where total energy reserves are greater [53]. The asphyxic state is likely to result in complex biochemical shifts within the cochlea. These would include the accumulation of metabolic waste products such as lactic acid [40] and $\mathrm{CO}_{2}$ which may in turn result in $\mathrm{pH}$ shifts within the cochlear fluids and within individual cells.

Among hypotheses which may account for FTC tip vulnerability, three seem particularly viable. First, the vulnerability could be due, in part, to the reduced value of EP and/or the changed value of the intracellular resting potential having an influence on voltage sensitive conductances in hair cells. Lewis and Hudspeth [23] have demonstrated the existence of such conductances in frog sacculus hair cells which could be present in both types of mammalian hair cells. Voltage sensitivity of membrane conductance is usually modeled by config. urational change or aggregation of proteins or glycoproteins inserted into the membrane lipid bilayer, and these gating processes can have different rate constants [27]. Some evidence now exists in support of voltage sensitive tuning in the organ of Corti [19,28-30], but observations on frequency independent performance of IHCs during intracellular current injection [30] suggest that it is the outer hair cell which is responsible for such voltage sensitivity. Since rate constants of membrane gating processes may be on the order of fractions of milliseconds $[23,27]$ and electric cur rent induced tuning effects occur and recover im- mediately [30], the long recovery time from asphyxia required by the IHC receptor potentials cannot be due only to these voltage sensitive processes. However, channel gating is also a function of ionic species and concentrations bathing the membrane. For example, both $\mathrm{Ca}^{2+}$ and membrane potential participate in activating a $\mathrm{K}^{+}$ conductance in frog hair cells [23]. Thus, if cell handling of calcium were hampered by an energy shortfall during hypoxia, delayed effects on membrane conductances could be postulated.

As a second possible functional target of asphyxia, extracellular $\mathrm{pH}$, or extracellular ion concentrations could influence the mechanical coupling between the IHC and the tectorial membrane, or between inner and outer hair cells mediated by tectorial membrane changes. Some evidence for mechanical interaction of inner and outer hair cells has now been obtained $[3,4]$ in support of earlier hypotheses for such action $[26,44]$. Tectorial membrane properties in these schemes are a critical factor and although little is known about these properties the available data suggest the possibility of functional vulnerability. The physical size of the membrane is influenced by sodium concentration [21] and the electrical internal charge may be affected by local $\mathrm{pH}$ and ionic strength [47]. The gel-like nature of the tectorial membrane may predispose it to fluctuations in its mechanical properties under the influence of changing ionic strength or electric field as observed for some other gels [49]. It is of interest to note that the present study did not find a significant difference in performance change between asphyxia and the one case of hypoxia (nitrogen breathing). Asphyxia would presumably result in higher levels of local $\mathrm{CO}_{2}$.

A third, and possibly the most compelling rationale for action of the asphyxia, would be a metabolic influence directly on the hair cells. Thalmann et al. [53] have determined that the 'metabolic reserve' of the organ of Corti is high, taking into account glycogen, glucose, ATP, and P-creatine levels. And although Ryan et al. [38] have observed greater metabolic activity of $1 \mathrm{HCs}$ with loud sound, it is the outer hair cells that are particularly endowed with high glycogen levels [51] along with an abundance of mitochondria in some species [45]. 
Vosteen [55] has postulated that the organ of Corti may rely more on anaerobic glycolytic processes because of what were thought to be low oxygen levels at the hair cells (due to lack of a local vascular supply). Thalmann [52] proposed that anaerobic glycolysis could permit a superior responsiveness to energy demands with loud sound. However, evidence suggests that the organ of Corti has a reasonable oxygen supply via the perilymph $[22,41]$. Taken together with glycogen levels and the distribution of mitochondria, an interruption of the oxygen supply should lead to a change from aerobic to anaerobic glycolysis resulting in abnormally high levels of lactate within outer hair cells. Since high tissue levels of lactic acid have been linked with cell death in the brain [56] it is possible that moderate levels could reversibly alter intracellular biochemistry, perhaps by way of changes in $\mathrm{pH}$. Intracellular $\mathrm{pH}$ and $\mathrm{Ca}^{2+}$ are biochemically linked and appear to be important for some types of actin filament assembly $[1,7,57]$. Although high $\mathrm{Ca}^{2+}$ concentration does not seem to disrupt (solate) stereociliary core bundles [54], Flock et al. [16] note a mechanical influence at the cuticular plate. Thus, intracellular trapping of $\mathrm{Ca}^{2+}$ in metabolic deficiency, perhaps related to high intracellular $\mathrm{pH}$, could result in a delayed recovery of outer hair cell mechanical properties.

\section{Acknowledgements}

This research was supported by Public Health Service NIH Program Project Grant NS-05785 and Research Grants NS-15107 and NS-11731. The author wishes to thank J. Nadine Brown, Robert I. Masta and Margaret Reeves for their technical assistance. A preliminary report of this work was presented at the 20th Workshop for Inner Ear Biology, Geilo, Norway, September 1983.

\section{References}

1 Begg, D.A., Rebhun, L.I. and Hyatt, H. (1982): Structural organization of actin in the sea urchin egg cortex: Microvillar elongation in the absence of actin filament bundle formation. J. Cell Biol. 93, 24-32.

2 Bornschein, H. and Gernandt, B. (1950): Selective removal of the nerve discharge component of the cochlea potential during anoxia. Acta Physiol. Scand. 21, 82-95.
3 Brown, M.C. (1983): Cochlear neural and inner hair celt responses in the guinea pig: Effects of anesthesia, surgery, temperature, asphyxia and efferent stimulation. Doctoral thesis, University of Michigan.

4 Brown, M.C. and Nuttall, A.L. (1984): Efferent control of cochlea inner hair cell responses in the guinea pig. I. Physiol. (London) (in press).

5 Brown, M.C., Nuttall, A.L., Masta, R.I. and Lawrence, M. (1983): Cochlea inner hair cells: Effects of transient asphyxia on intracellular potential. Hearing Res. 9, 131-144.

6 Brown, M.C., Smith, D.I. and Nuttall, A.L. (1983): The temperature dependency of neural and hair cell responses evoked by high frequencies. J. Acoust. Soc. Am. 73. 1662-1670.

7 Burgess, D.R. and Prum, B.E. (1982): Reevaluation of brush border motility: Calcium induces core filament solation and microvillar vesiculation. I. Cell Biol. 94, 97-107

8 Dallos, P. (1983): Some electrical circuit properties of the organ of Corti: 1. Analysis without reactive elements. Hearing Res. 12, 89-119.

9 Davis, H. (1965): A model for transducer action of the cochlea. In: Cold Spring Harbor Symposia on Quantitative Biology, Vol. 30. Sensory Receptors

10 Davis, H., Fernandez, C. and McAuliffe, D.R. (1950): The excitatory processes in the cochlea. Proc. Natl. Acad. Sci U.S.A. $36,580-587$.

11 Evans, E.F. (1970): Narrow 'tuning' of cochlea nerve fiber responses in the guinea pig. J. Physiol (London) 206, 14-15.

12 Evans, E.F. (1974): Auditory frequency selectivity and the cochlea nerve. In: Facts and Models in Hearing, Communication and Cybernetics. Vol. 8. Editors: E. Zwicker and E. Terhardt. Springer-Verlag, New York.

13 Evans, E.F. (1979): Single-unit studies of mammalian cochlear nerve. In: Auditory Investigation: The Scientific and Technological Basis, Editor: H.A. Beagley. Oxford University Press, London.

14 Evans, E.F. and Wilson, J.P. (1973): Frequency selectivity of the cochlea. In: Basic Mechanisms of Hearing, Editor: A.R. Møller. Academic Press, New York.

15 Fernandez, C. and Alzate, R. (1959): Modifications of cochlear responses by oxygen deprivation. Arch. Otolaryn. gol. $69,82-94$

16 Flock, A., Bretscher, A. and Weber, K. (1982): Immunohistochemical localization of several cytoskeletal proteins in inner ear sensory and supporting cells. Hearing Res. 6. $75-89$.

17 Goodman, D.A., Smith, R.L. and Chamberlain, S.C. (1982): Intracellular and extracellular responses of the organ of Corti of the gerbil. Hearing Res. 7, 161-179.

18 Harrison, R.V. and Evans, E.F. (1977): The effects of hair cell loss (restricted to outer hair cells) on threshold and tuning properties of cochlear fibers in the guinea pig. In: INSERM, Vol. 68. Editors: M. Portmann and J.-M. Aran.

19 Hubbard, A.E., Voigt, H.F. and Mountain, D.C. (1983): Injection of direct current into scala media alters auditorynerve response properties. Sixth Midwinter Research Meeting, Assac. Res. Otolaryngol. January 1983, St. Petersburg Beach, Florida. 
20 Kiang, N.Y.-S., Liberman, M.C. and Levine, R.A. (1970): Auditory nerve activity in cats with normal and abnormal cochleas. In: Sensory Neural Hearing Loss. Editor: J. Knight. Churchill Press, London.

21 Kronester-Frei, A. (1979): The effect of changes in endolymphatic ion concentrations on the tectorial membrane. Hearing Res. 1, $81-94$.

22 Lawrence, M. and Nuttall, A.L. (1972): Oxygen availability in the tunnel of Corti measured by microelectrode. J. Acoust. Soc. Am. 52, 566-573.

23 Lewis, R.S. and Hudspeth, A.J. (1983): Voltage- and iondependent conductances in solitary vertebrate hair cells. Nature (London) 304, 538-541.

24 Liberman, M.C. and Kiang, N.Y.-S. (1978): Acoustic trauma in cats. Acta Otolaryngol. Suppl. 358, 1-63.

25 Masrahy, G.A., Shimabarger, E.W. and Arnold, J.E. (1958): Changes in the cochlea endolymphatic oxygen availability, action potential, and microphonics during and following asphyxia, hypoxia, and exposure to loud sounds. J. Acoust. Soc. Am. 30, 701-704.

26 Mountain, D.C. (1980): Changes in endolymphatic potential and crossed olivocochlear bundle stimulation alter cochlear mechanics. Science 210, 71-72.

27 Mueller, P. (1975): Electrical excitability in lipid bilayers and cell membranes. In: Energy Transducing Mechanisms. Editor: E. Racher. MTP International Rev. Sci.: Biochemistry. Series One, Vol. 3. Butterworth and Co., London.

28 Nuttall. A.L. (1983): Inner hair cell de receptor potential changes from direct currents introduced into the guinea pig cochlea. Abstract, Sixth Midwinter Research Meeting, Assoc, Res. Otolaryngol. January 1983, St. Petersburg Beach, Florida.

29 Nuttall, A.L. (1984): Inner hair cell sensitivity changes induced by intracellular direct current injection. Abstract Seventh Midwinter Research Meeting, Assoc. Res. Otolaryngol. February 1984, St. Petersburg Beach, Florida.

30 Nuttall. A.L. (1984): Influences direct current on de on receptor potentials from cochlear inner hair cells in the guinea pig. I. Acoust. Soc. Am. (in press).

31 Patuzzi, R. and Sellick, P.M. (1983): A comparison between basilar membrane and inner hair cell receptor potential input-output functions in the guinea pig cochlea. $J$. Acoust. Soc. Am. 74, 1734-1741.

32 Patuzzi, R., Johnstone, B.M. and Sellick, P.M. (1984): The alteration of the vibration of the basilar membrane produced by loud sound. Hearing Res. 13, 99-100.

33 Prazma, J., Fischer, N.D., Biggers, W.P. and Ascher, J. (1978): A correlation of the effects of normoxia, hyperoxia. and anoxia on $\mathrm{PO}_{2}$ of endolymph and cochlea potentials. Hearing Res. 1, 3-9.

34 Rhode, W.S. (1971): Observations on the vibration of the basilar membrane in squirrel monkeys using the Mössbauer technique. J. Acoust. Soc. Am. 49, 1218-1231.

35 Robertson, D. and Manley, G. (1974): Manipulation of frequency analysis of the cochlea and ganglion of the guinea pig. J. Comp. Physiol. 91, 363-375.

36 Russell, I.J. and Cowley, E.M. (1983): The influence of transient asphyxia on receptor potentials in inner hair cells of the guinea pig cochlea. Hearing Res. 11, 373-384.

37 Russell, I.J. and Sellick, P.M. (1978): Intracellular studies of hair cells in the mammalian cochlea. J. Physiol. (London) $284,261-290$.

38 Ryan, A.F. Sharp. F.R., Woolf, N.K. and Davidson. T.M. (1983): Deoxyglucose uptake in the cochlea during silence and noise: Localization at the cellular level with ${ }^{3} \mathrm{H}$ autoradiography. Abstract, Sixth Midwinter Mecting. Assoc. Res. Otolaryngol. January 1983. St. Petersburg Beach, Florida.

39 Salvi, R.J., Hamernik, R.P. and Henderson, D. (1983): Response patterns of auditory nerve fibers during temporary threshold shift. Hearing Res. 10, 37-67.

40 Scheibe, F., Haupt, H., Rothe, E and Hache, U. (1981): Postmortale veränderungen der Laktat- und Pyruvatkonzentration in der Perilymphe des Meerschweinchens. Arch. Acta Otorhinolaryngol. 232, 293-297

41 Schnieder, E-A. (1974): A contribution to the physiology of the perilymph, part 1: The origins of perilymph. Ann. Otol. 83. 76-83.

42 Sellick, P.M. and Russell, I.J, (1979): Intracellular studies of the receptor potentials of inner hair cells of the guinea pig cochlea: Techniques. In: Auditory Investigation: The Scientific and Technological Basis. Editor: H.A. Beagley. Oxford University Press, London.

43 Sellick, P.M., Patuzzi, R. and Johnstone, B.M. (1982); Measurement of basilar membrane motion in the guinea pig using Mössbauer technique. J. Acoust. Soc. Am. 72 , $131-141$

44 Siegel, J.H. and Kim, D.O. (1982): Efferent control of cochlear mechanics? Olivocochlear bundie stimulation affects cochlea biomechanical nonlinearity. Hearing Res. 6, $171-182$.

45 Smith. C.A. (1978): Structure of the cochlear duct. In: Evoked Electrical Activity in the Auditory Nervous System. Editor: R. Naunton. Academic Press, New York.

46 Spoendlin, H. (1969): Innervation patterns in the organ of Corti of the cal. Acta Otolaryngol. 67, 239-254.

47 Steel, K.P. (1983): Donnan equilibrium in the tectorial membrane. Hearing Res. 12, 265-272.

48 Strelioff, D, (1973): A computer simulation of the generation and distribution of cochlear potentials. J. Acoust. Soc. Am. 54, 620-629.

49 Tanaka, T., Ishiwata, S. and Ishimoto, C. (1977): Critical behaviour of density fluctuations in gels. Physical Rev. Lett. $38,771-774$.

50 Tasaki, I., Davis, H. and Eldredge, D.H. (1954): Exploration of cochlear potentials in the guinea pig. J. Acoust. Soc. Am. 26, 765 773 .

51 Thalmann, R. (1972): Recent refinements of quantitative chemical analysis of tissues in cells of the inner ear. Acta Otolaryngol. 73, 160-174.

52 Thalmann, R. (1975): Biochemical studies of the auditory system. In: The Nervous System. Editor: D.B. Tower. Vol. 3 of Human Communication and Its Disorders. Raven Press, New York.

53 Thalmann, R., Kusakari, J. and Miyoshi, T. (1973): Dys- 
functions of energy releasing and consuming processes of the cochlea. Laryngoscope $83,1690-1712$.

54 Tilney, L.G., DeRosier, D.J. and Mulroy, M.J. (1980): The organization of actin filaments in the stereocilia of cochlear hair cells. J. Cell Biol. 86, 244-259.

55 Vosteen, K.H. (1961): Neue Aspekte zur Biologie und Pathologie des Innenohres. Arch. Ohren Nasen-Kehlkopfheilkd. 178, 1-104.
56 Wagner, K.R. and Myers, R.E. (1979): Topographic aspects of lactic acid accumulation in brain tissue during circulatory arrest. Abstract, CBF-6, Neurology 29, 2196.

57 Weber, K and Glenney, J.R. (1982): Calcium-modulated multifunctional proteins regulating $\mathrm{F}$-actin organization. Cold Spring Harbor Symposia on Quantitative Biology. Vol. 46, Pt. 2. 